\title{
Legislar para proteger: Lei Sena, a primeira lei de saúde mental em Portugal (1889)
}

Legislate to protect: Lei Sena, the first mental health law in Portugal (1889) Legislar para proteger: Ley Sena, la primera ley de salud mental en Portugal (1889)

Analisa Candeias ${ }^{1,2,3}$

iDhttps://orcid.org/0000-0001-9620-163X

Ermelinda Macedo ${ }^{1,2}$

iDhttps://orcid.org/0000-0003-4053-2864

Alexandra Esteves ${ }^{4,5}$

iDhttps://orcid.org/0000-0003-0660-9485

Luís Sá ${ }^{6,7}$

iDhttps://orcid.org/0000-0001-9687-413X

${ }^{1}$ Escola Superior de Enfermagem da Universidade do Minho, Braga, Portugal

${ }^{2}$ Unidade de Investigação em Ciências da Saúde: Enfermagem (UICISA: E), Escola Superior de Enfermagem de Coimbra (ESEnfC), Coimbra, Portugal

${ }^{3}$ Centro de Investigação Interdisciplinar em Saúde, Universidade Católica Portuguesa, Porto, Portugal

${ }^{4}$ Universidade Católica Portuguesa, Faculdade de Filosofia e Ciências Sociais, Braga, Portugal

${ }^{5}$ Lab2PT - Instituto de Ciências Sociais da Universidade do Minho, Braga, Portugal

${ }^{6}$ Universidade Católica Portuguesa, Instituto de Ciências da Saúde, Porto, Portugal

${ }^{7}$ Centro de Investigaçấo Interdisciplinar em Saúde, Universidade Católica Portuguesa, Porto, Portugal

Autor de correspondência

Analisa Candeias

E-mail: acandeias@ese.uminho.pt

Recebido: 01.07.20

Aceite: 26.10 .20

\section{Resumo}

Contexto: A psiquiatria em Portugal ganhou relevo como ciência nos anos de oitocentos, sendo criada legislação importante nesse âmbito e, embora os enfermeiros fossem praticantes da assistência nas diversas instituições de saúde, foi igualmente nessa época que a enfermagem nasceu como profissão.

Objetivos: Analisar a lei em apreço; indicar a sua importância no desenvolvimento da psiquiatria e da saúde mental em Portugal; identificar contributos para a história da enfermagem de saúde mental e psiquiátrica portuguesa.

Metodologia: Investigação histórica, utilizando-se como fonte a Lei de 4 de julho de 1889, Diário do Governo n. ${ }^{\circ} 155$ de 15 de julho de 1889.

Resultados: Pretendia-se que a assistência dos alienados em Portugal fosse legislada e organizada, criando-se estruturas próprias para esse efeito. Contudo, as intervençóes previstas a nível legislativo nunca foram concretizadas e o país manteve défices na assistência dos alienados até ao final do século XIX.

Conclusáo: A lei analisada foi importante para o desenvolvimento da saúde mental e da psiquiatria portuguesa, visto ter sido o primeiro documento legal emanado nesse domínio.

Palavras-chave: história da enfermagem; psiquiatria; saúde mental; legislação

\section{Abstract}

Background: Psychiatry gained ground as a science in the $19^{\text {th }}$ century, in Portugal, and important laws were created in this context. Although nurses were care providers in various health institutions, it was also at this time that nursing was born as a profession.

Objectives: To analyze the law presented; to explain its importance in the development of psychiatry and mental health in Portugal; to identify its contributions to the history of Portuguese psychiatric and mental health nursing.

Methodology: Historical research, using as source the Law of 4 July 1889, Government Gazette No. 155 of 15 July 1889.

Results: In Portugal, there was a need for the legislation and organization of care provision to the insane, creating structures suitable for this purpose. However, the legislative interventions planned were never implemented, and thus poor care was provided to the insane in Portugal until the end of the $19^{\text {th }}$ century.

Conclusion: This law was important for the development of mental health and psychiatry in Portugal because it was the first legal document issued in this domain.

Keywords: history of nursing; psychiatry; mental health; legislation

Resumen

Contexto: La psiquiatría en Portugal se desarrolló como ciencia en el siglo XIX, se creando una importante legislación en esta área y, si bien los enfermeros eran practicantes de asistencia en las instituciones de salud, fue también en ese momento cuando nació la enfermería como profesión.

Objetivos: Analizar la ley presentada; mostrar su importancia en el desarrollo de la psiquiatría y de la salud mental en Portugal; identificar contribuciones para la historia de la enfermería de salud mental y psiquiátrica portuguesa.

Metodología: Investigación histórica, utilizándose como fuente la Ley del 4 de julio de 1889, Diário do Governo n. ${ }^{\circ} 155$ de 15 de julio de 1889.

Resultados: Se pretendía legislar y organizar la asistencia de los enajenados en Portugal, mediante la creación de estructuras para tal fin. Sin embargo, las intervenciones previstas a nivel legislativo nunca se llevaron a cabo y el país mantuvo déficits en la asistencia a los enajenados hasta finales del siglo XIX. Conclusíon: La ley analizada fue importante para el desarrollo de la salud mental y la psiquiatría portuguesa, ya que fue el primer documento legal emitido en esta área.

Palabras-clave: historia de la enfermería; psiquiatria; salud mental; legislación
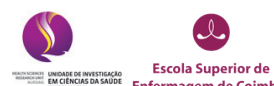


\section{Introdução}

O investimento no estudo e desenvolvimento da psiquiatria tem uma história recente em Portugal. A humanização no âmbito das instituiçóes que albergavam os alienados em terras portuguesas foi-se dando ao longo do século XIX (Barahona, 1984; Esteves, 2018), influenciada tanto pelas viagens através da Europa e ideias vanguardistas de diversos médicos, dos quais são exemplo Bernardino António Gomes, Francisco Martins Pulido ou António Maria de Sena, como pelos movimentos políticos agilizados em função das duras realidades vividas nas instituiçōes onde residiam os alienados (Pereira, 1986).

A visão da psiquiatria como ciência veio a tomar forma no país apenas nas últimas décadas do século XIX, embora a partir da primeira década da centúria seguinte se tivesse afirmado com uma maior robustez (Esteves, 2018). Foi igualmente no século XIX que a enfermagem nasceu como profissão em Portugal, tendo em conta o primeiro curso desenvolvido nos Hospitais da Universidade de Coimbra em 1881, pelas mãos de António Augusto da Costa Simóes (Lopes \& Rodrigues, 2009a).

No entanto, sabemos que existiam alienados internados no Hospital Real de Todos os Santos já em 1539, ao cuidado do Padre Pedro Fernando de Gouveia, e sabemos igualmente que, após o terramoto de 1755, os alienados que vagueavam na cidade de Lisboa foram albergados num hospital de construção provisória, na Enfermaria de São João de Deus (Direção do Hospital Miguel Bombarda, 1949). Posteriormente, foram transferidos para as enfermarias de São Teotónio (para homens) e Santa Eufémia (para mulheres), no Hospital de São José (Barahona, 1984). Nesse hospital era albergada parte dos alienados portugueses (Pereira, 1986) e, devido à sobrelotação das enfermarias mencionadas, os cuidados e os tratamentos a estes doentes, que eram habitualmente praticados pelos enfermeiros, foram-se deteriorando e escasseando.

Num relatório realizado a pedido da Coroa, Bernardino António Gomes descreveu, em 1843, as más condiçôes da enfermaria feminina do Hospital de São José:

quem terá entrado huma vez na divisão de alienados de S. José, especialmente a parte consagrada ás mulheres que deixe de sahir com o coração opprimido de observar tanta miseria: doidas nuas e desgrenhadas, entregues a todos os seus desvarios, gritando e gesticulando, encerrado às vezes em hum cubículo escuro e infecto, onde mal podem obter hum feixe de palha em que possam revolver-se. (Gomes, 1999, p. 143)

Acrescentou que o local era exíguo, com pouca luz e ventilação inapropriada, coabitando nesse espaço cerca de 150 alienadas, assistidas por três serventes, número reduzido para os cuidados que as mesmas exigiam.

Em 1848, após diversas divergências políticas e administrativas, o Duque de Saldanha apresentou um papel essencial na defesa dos alienados (Barahona, 1984; Sena, 2003). Foi então iniciada a transferência dos alienados do Hospital de São José para o Convento de São Vicente de Paulo, antiga Quinta de Rilhafoles, denominado na altura Hospital de Rilhafoles. Este foi o primeiro hospital psiquiátrico nacional e considerado como uma das primeiras medidas assistenciais na esfera da psiquiatria e saúde mental no país. Nesse ano, foram transferidas, primeiramente, as alienadas internadas na Enfermaria de Santa Eufémia e posteriormente, em 1850, os alienados que se encontravam na Enfermaria de Sáo Teotónio. Porém, em 1851 existiam já 322 alienados em Rilhafoles, 159 homens e 163 mulheres, provindos de todos os distritos portugueses (Pulido, 1851), e depressa esse hospital, que se manteve sob a alçada administrativa de São José ao longo desse período, ficou sobrelotado e sobrecarregado. Estes doentes eram assistidos por enfermeiros, ajudantes de enfermeiro e serventes, que compunham o corpo de enfermeiros de Rilhafoles.

Considerada uma necessidade nacional, assumia-se como urgente a edificação de uma instituiçáo que viesse ampliar a assistência dos alienados portugueses. A construção de estruturas que fossem apenas dedicadas à assistência dos alienados foi uma tendência internacional - vejam-se, por exemplo, as datas de inauguração das instituições apresentadas na obra Lunacy in Many Lands, de George A. Tucker (Tucker, 1887). Se, por um lado, o país revelava algum atraso na atençáo que concedeu à ciência psiquiátrica, por outro lado seguiu a tendência de outros países, considerados até mais avançados nesse âmbito, e edificou uma instituição de raiz que visava proporcionar essa assistência específica, o Hospital de Alienados do Conde de Ferreira.

Joaquim Ferreira dos Santos, conhecido por Conde de Ferreira, faleceu em 1866, e, à sua morte, foi legada parte da sua fortuna pessoal para construçáo de um edifício para a assistência de alienados, no Porto, que ficou sob a administração da Santa Casa da Misericórdia da cidade. Tal como em Lisboa, na cidade do Porto os alienados eram recolhidos num hospital geral, o Hospital de Santo António (Pereira, 1986), que se encontrava igualmente sob a alçada da Santa Casa da Misericórdia, num espaço designado como Porão (Barahona, 1984).

Em 1883 foi entáo inaugurado esse edifício, o Hospital de Alienados do Conde de Ferreira, sendo António Maria de Sena o seu primeiro diretor clínico. Este médico, nascido em Seia em 1845, formou-se em Medicina em 1876, tendo, à altura da sua formação médica, estudos superiores em Teologia, Filosofia e Matemática (Cardoso, 2008). Foi professor na Universidade de Coimbra e, em 1878, foi-lhe concedida uma bolsa de estudos que lhe permitiu viajar pela Europa e conhecer métodos pedagógicos utilizados noutros países (e.g. França, Alemanha, Áustria), assim como as realidades hospitalares dos mesmos, inteirando-se das novidades relativamente à assistência dos alienados. António Maria de Sena tomou posse como diretor clínico desse hospital no Porto em 1881, embora o mesmo ainda estivesse em construção. A sua estrutura foi influenciada pelas novidades que o alienista absorveu da viagem que efetuou pela Europa. Em 1887, Sena foi eleito deputado por Viana do Castelo (Barahona, 1984; Cardoso, 2008), e a sua ação na Câmara dos Pares foi orientada para a melhoria da assistência e alargamento da proteção aos alienados e aos criminosos considerados doentes mentais. Em 1889 foi aprovada uma lei delineada por António 
Maria de Sena, habitualmente designada de Lei Sena, que visava a organização dos serviços de saúde dirigidos aos alienados, e que foi considerada como o primeiro documento legislativo em Portugal no âmbito da psiquiatria e da saúde mental, compreendendo a criaçáo de um suporte legislativo para organizar e alicerçar a assistência desses doentes.

Tendo em conta a problemática apresentada, é importante estudar a Lei Sena numa perspetiva histórica e dar-lhe destaque, visto que foi considerada como vanguardista à época e tendo-se apresentado como o ponto de partida para o desenvolvimento legislativo específico da assistência dos alienados em território português. Para a concretização deste estudo foram tidas em consideração as seguintes etapas na produção de trabalho histórico: recomposição das circunstâncias históricas partindo das fontes, o relacionamento dessas circunstâncias entre si e a compreensão das mesmas. O objetivo geral deste trabalho passa por dar a conhecer esse documento legal, sendo os objetivos específicos do mesmo analisar a Lei de 4 de julho de 1889, do Diário do Governo n. ${ }^{\circ} 155$ de 15 de julho do mesmo ano (Lei Sena), apresentada na Câmara dos Pares e aprovada pelo Rei D. Luiz I, indicar a sua importância no desenvolvimento da psiquiatria e da saúde mental em Portugal e identificar contributos para a história da enfermagem de saúde mental e psiquiátrica portuguesa.

\section{Metodologia}

Desenvolver o presente e preparar o futuro significa conhecer o passado, aprendendo com o mesmo e respeitando a evolução que tem sido efetuada. Aquando a preparação de um trabalho de investigação histórica, devemos ter em conta não somente aquilo que nos é mais agradável, porém igualmente aquilo que coloca em causa as nossas interpretações da realidade (Mattoso, 1997). Deste modo, este tipo de investigação pode ser igualmente entendido como um desafio, visto que o estudo do crescimento da profissão, e da legislação que o influenciou, permite um desenvolvimento interno daquilo que pode ser, ou é, a enfermagem (Ferreira et al., 2013), e nesta esfera concreta, a enfermagem de saúde mental e psiquiátrica.

Este trabalho deriva, então, de um estudo histórico, posicionado num enquadramento qualitativo, tendo-se utilizado a pesquisa e análise documental (Junior, 2011), atendendo às etapas de produção de trabalho histórico e aos objetivos supra apresentados. Para procedermos a esta investigaçáo, tomámos como fonte a Lei de 4 de julho de 1889, do Diário do Governo n. ${ }^{\circ} 155$ de 15 de julho do mesmo ano, que se encontra disponível em formato PDF no site da Legislação Régia da Assembleia da República (em https://legislacaoregia.parlamento.pt/), documento que foi acedido no dia 1 de maio de 2020, sendo realizado um download do mesmo para análise. Para a realização dessa análise tivemos em conta que, nos dias correntes, "são considerados documentos todos os vestígios do passado, passíveis de análise histórica" (Junior, 2011, p. 339). Isto pressupóe um estímulo para os enfermeiros estarem alertas no que diz respeito aos documentos essenciais para entenderem a sua profissão, dos quais fazem parte as manifestaçóes legislativas, como é o caso da lei em estudo, tendo esses profissionais de saúde de se encontrarem cientificamente capacitados para os saberem identificar. Esta capacitação prevê um caminho de amadurecimento na esfera da investigação histórica em enfermagem, que nos últimos anos se tem vindo a realizar de forma mais ampla.

\section{Resultados e Discussão}

Antes de apresentarmos os resultados da análise da Lei de 4 de julho de 1889, é necessário efetuarmos uma breve apresentação relativa à recomposição das circunstâncias históricas partindo das fontes da época que visaram a assistência dos alienados, tendo em conta as etapas da produção de um trabalho histórico. Começamos essa apresentação por António Maria de Sena, que defendeu a inexistência de condiçóes no país para a assistência psiquiátrica e defendeu a obrigaçáo do Governo na criação de estruturas físicas que albergassem os alienados espalhados pelo país, incluindo os alienados considerados criminosos (Sena, 2003). Sena referiu ainda que os alienados considerados suspeitos da prática de crimes ou já condenados, e que se encontravam no Hospital de Rilhafoles, deveriam ser "os que estão pior alojados. A casa é velhíssima. Sem conforto nem agasalho. A mobília reduz-se a uma tarimba formada de tábuas velhas, assentes em pés de ferro, tudo tosco, velho e sujo" (Sena, 2003, p. 142). Sena indicava assim que esses doentes necessitariam de um apoio extraordinário e uma assistência específica, devendo ser acompanhados e vigiados continuamente, vigilância essa que, habitualmente, era realizada pelos enfermeiros nas instituiçóes de saúde que os assistiam.

O debate sobre afinidade entre a alienação e a responsabilidade criminal não foi uma novidade que veio à tona na centúria de oitocentos. Pelo contrário, esse debate existia já há anos, porém tomou novas formas nessa época, tendo como intervenientes de destaque, no âmbito da saúde, Júlio de Matos e Miguel Bombarda (Esteves, 2018). No entanto, foi com António Maria de Sena que o país conseguiu o primeiro ato legislativo que, relativamente a essa matéria, vinha clarificar a relaçáo entre a medicina e o direito - embora no Código Penal Português de 1886, no Artigo 42..$^{\circ}$ e Artigo 43. ${ }^{\circ}$, a título de exemplo, fosse determinado que não eram suscetíveis de imputação criminal os alienados sem intervalos lúcidos e os alienados que, embora apresentassem intervalos lúcidos, cometessem um crime num estado de loucura (República Portuguesa, 1919).

A assistência dos alienados, a partir de meados do século XIX, estava concentrada no Hospital de Rilhafoles e no Hospital de Alienados do Conde de Ferreira (Lopes \& Rodrigues, 2009b). Nessas duas instituiçóes os enfermeiros eram considerados essenciais para manter a excelência na qualidade da assistência e para a aplicação de bons cuidados (Sena, 1887; Pulido, 1851). Podiam existir ainda, nos diversos hospitais gerais, leitos ou enfermarias reservados para estes doentes. Existiam, além disso, casas 
de saúde ou casas de particulares que também recebiam alienados, que eram, usualmente, pessoas endinheiradas ou pertencentes a famílias que pagavam por esses serviços, conseguindo assim ser escondidos da sociedade burguesa da época, que pautava os bons costumes e não via com bons olhos os escândalos sociais ou públicos. As prisões eram igualmente espaços onde se encontravam alienados, embora estes não fossem bem acolhidos pelos restantes reclusos, devido à tendência que apresentavam para criar desacatos. Em 1893 surgiu a Casa do Sagrado Coraçáo de Jesus, pertencente à Ordem Hospitaleira dos Irmấos de S. João de Deus, e, em 1894, abriu portas a Casa de Saúde da Idanha, pertencente à Congregação das Irmãs Hospitaleiras do Sagrado Coração de Jesus, instituiçôes que vieram facilitar a assistência dos alienados portugueses. À semelhança de Rilhafoles, no Hospital de Alienados do Conde de Ferreira o corpo de enfermeiros, laico, era composto hierarquicamente por enfermeiros, ajudantes de enfermeiro e criados (Sena, 1887). Estes funcionários das enfermarias tinham como deveres vigiar e controlar os alienados, promovendo as rotinas diárias, que eram marcadas pelos tempos dos tratamentos, das refeiçóes e do descanso. Eram igualmente responsáveis pela gestão das enfermarias e dos espaços anexos que as compunham. Nas casas religiosas a assistência desses doentes era efetuada pelos irmãos e irmãs, gente consagrada que se tinha dedicado a este serviço. Estes praticantes da assistência eram essenciais nas instituiçóes que albergavam exclusivamente os alienados, visto que eram os responsáveis pela vigilância, pelo cumprimento das normas, pela manutenção do equilíbrio assistencial e por assegurar que a assistência era bem efetuada.

Na segunda metade do século XIX, foi realizado por António Maria de Sena um estudo estatístico a nível nacional relativo ao número de alienados existente em Portugal, seus antecedentes e ao local onde os mesmos se encontravam acolhidos (Sena, 2003). Apesar náo incluirmos todos os distritos do país nesta apresentação, referimos que o distrito com maior número de alienados era o Porto, com 1078 doentes, seguido por Viseu, com 775, apresentando o distrito de Lisboa 727 alienados. Sena comprovou ainda que Rilhafoles, inicialmente dimensionado para albergar os alienados de todo o país, recebia internamentos, na sua maioria, provindos do distrito de Lisboa (Sena, 2003). Já entre 1883 e 1885, no Hospital de Alienados do Conde de Ferreira, a população de alienados era proveniente sobretudo do Norte do país, em particular dos distritos de Porto, Braga e Viseu, tendo o distrito de Lisboa uma representatividade residual (Sena, 1887). Desta forma, reconhecemos que a assistência dos alienados em Portugal se encontrava desordenada e os pontos principais de apoio específico para esses doentes se alocavam apenas a duas cidades, Lisboa e Porto. Aqueles que não se encontravam perto dessas zonas geográficas tinham de se deslocar através do país para lhes ser garantida uma assistência de maior qualidade e exclusivamente dirigida aos seus problemas de saúde.

Passamos agora à apresentação dos resultados da análise da Lei Sena e continuamos o registo da produçáo de trabalho histórico naquilo que diz respeito ao relacio- namento das circunstâncias históricas e a compreensão das mesmas. Essa lei foi aprovada a 4 de julho de 1889 e publicada no Diário do Governo n. ${ }^{\circ} 155$ de 15 de julho, sendo a primeira legislação de assistência psiquiátrica a nível nacional, cujo arquiteto, como já mencionámos anteriormente, foi António Maria de Sena, que defendia a necessidade da existência de um documento que viesse organizar a assistência psiquiátrica no país. Nesta lei preconizava-se que Portugal fosse dividido em quatro círculos assistenciais: i) o primeiro constituído pelos distritos de Viana do Castelo, Braga, Bragança, Vila Real, Porto e Aveiro; ii) o segundo pelos distritos de Coimbra, Viseu, Guarda, Castelo Branco e Leiria; iii) o terceiro pelos distritos de Santarém, Lisboa, Portalegre, Évora, Beja, Faro e Funchal; iv) e, o último, pelos distritos da Horta, Angra do Heroísmo e Ponta Delgada. De notar que, e efetuando uma comparação, em alguns países europeus este tipo de documento legislativo tinha sido elaborado ainda na primeira metade do século XIX. O Reino Unido, por exemplo, aprovou em 1845 uma lei especifica neste âmbito, habitualmente designada Lunatics Act (Brimblecombe, 2005).

De acordo com a lei aqui analisada, o governo português era autorizado a construir e mobilar diversos estabelecimentos para alienados e, de acordo com o seu Artigo $2 .^{\circ}$ - artigo que explanava a concretizaçáo dos círculos de assistência -, devia ser construído em Lisboa um hospital para 600 pessoas, com duas enfermarias próprias para alienados criminosos, uma para homens e outra para mulheres. Em Lisboa deveriam também existir condições para o ensino da clínica psiquiátrica. Em Coimbra, à semelhança do modelo da capital, deveria ser construído um hospital para 300 pessoas e outro na ilha de $S$. Miguel, para 200 pessoas. Tendo em conta a realidade de Rilhafoles e do Hospital de Alienados do Conde de Ferreira, era óbvio que, nesses espaços, os enfermeiros seriam então os agentes assistenciais com maior relevo no âmbito do funcionamento das enfermarias. A construção de grandes edifícios para albergar um número elevado de alienados tornou-se comum a nível internacional nos anos de oitocentos (Tucker, 1887), tal como igualmente se vulgarizou a sobrelotação desses espaços. Veja-se, por exemplo, o caso do manicómio de Malta no século XIX, em que a sobrelotaçáo levava a que os alienados fossem acomodados nas casas-de-banho, na casa mortuária ou até nos vãos das escadas (Chircop, 2013).

$\mathrm{Na}$ região do Porto, seguindo a linha do mesmo Artigo 2. ${ }^{\circ}$, devia ser construído (ou encontrado) um edifício para instalar um asilo para "duzentos idiotas, epilepticos e dementes inoffensivos dos dois sexos" (Lei de 4 de julho de 1889 do Diário do Governo n. ${ }^{\circ} 155$ de 15 de julho de 1889). O Hospital de Alienados do Conde de Ferreira, inaugurado seis anos antes da aprovação desta lei, tinha capacidade para cerca de 300 pessoas. Em 1889, nesse hospital, estavam internados 392 alienados, 203 homens e 189 mulheres, tendo apenas saído como curados, entre 1888 e 1889, quinze alienados (Santa Casa da Misericórdia do Porto, 1889). Por último, ainda em relação ao Artigo 2..$^{\circ}$, era preconizada a construção de enfermarias anexas às penitenciárias centrais do país para o tratamento de 
alienados, mas que até ao final do século XIX ainda não tinham sido edificadas (Esteves, 2018). O Hospital de Rilhafoles, que se encontrava em situação de sobrelotação, seria convertido, de acordo com a Lei Sena, num asilo para 300 alienados com caraterísticas semelhantes ao asilo que deveria ser construído no Porto.

Considerando ainda o documento legislativo em estudo, se um alienado fosse diagnosticado ou encontrado em algum dos círculos que não fosse o da sua zona de residência era considerado indigente ou vagabundo $e$ deveria ser enviado para a respetiva região de assistência. Caso fosse internado fora do seu círculo, o pagamento do tratamento devia ser realizado pela instituição que era suposto tê-lo recebido. Os alienados pensionistas, ou seja, aqueles que pagavam o seu próprio tratamento (ou em que o mesmo era providenciado pelas suas famílias), podiam ser recebidos em círculos que náo o da sua zona residencial. No entanto, não era possível retirar o lugar, nas instituiçóes dos círculos definidos, àqueles que necessitavam de tratamento e não o podiam pagar. Se, por um lado, as receitas provenientes dos pensionatos ampliavam a capacidade financeira das instituiçóes que acolhiam alienados e ajudavam a suportar as despesas (Sena, 1887), por outro lado, estas instituiçóes, com o acolhimento de indigentes, cumpriam a sua função social, que passava por assistir os alienados que náo encontravam lugar na sociedade. Esta dualidade assistencial, sendo uma parte paga e outra de natureza caritativa, foi comum aos hospitais psiquiátricos portugueses nos anos de oitocentos, sendo até prolongada pela centúria seguinte.

Regressando ao tópico dos alienados criminosos, estes deviam ser acolhidos nas enfermarias das penitenciárias centrais e nas duas enfermarias do hospital que seria construído em Lisboa. Nas primeiras, de acordo com a Lei Sena, seriam acolhidos:

$1 .^{\circ}$ Os condemnados a penas maiores que apparecerem alienados ou epipleticos durante o cumprimento da pena; $2 .^{\circ}$ Os indiciados ou pronunciados por crimes a que correspondem penas maiores, quando tenha sido ordenado o exame medico legal (...); 3. ${ }^{\circ}$ Todos os indiciados ou pronunciados por crimes a que correspondam penas maiores, quando apparecerem alienados no periodo que decorre desde a instauração do processo até ao julgamento. (Lei de 4 de julho de 1889, p. 318).

Nas enfermarias do hospital a construir em Lisboa, de acordo com a lei em estudo, seriam acolhidos os indivíduos absolvidos, ou cujo processo tivesse sido suspenso, por motivos de alienaçáo mental e os indivíduos que, encontrando-se nas enfermarias das penitenciárias centrais à altura da expiração da pena, fossem considerados como perigosos, não podendo ser enviados para o círculo de assistência respetivo. $\mathrm{O}$ exame médico-legal devia ser realizado aquando suspeita de alienação mental do réu, que permitiria dirimir o crime ou suspender o processo legal - neste caso, a avaliaçáo seria realizada por peritos, num estabelecimento próprio para alienados. De facto, ainda que a lei aqui estudada não tenha sido concretizada durante os anos seguintes à sua aprovação, a verdade é que estes exames foram sendo realizados nas instituições que assistiam os alienados (Esteves, 2018; Sena, 1887), tendo como principais intervenientes avaliadores os alienistas que as dirigiam.

No que diz respeito ao financiamento da criação dos círculos assistenciais e da construção dos asilos e hospitais, de acordo com a Lei Sena, seria criado um fundo de beneficência pública para os alineados portugueses. Este fundo era financiado por um imposto especial de selo, no valor de $4 \$ 500,15 \$ 000,12 \$ 000$ e $1 \$ 000$ réis, respetivamente, sobre os documentos relativos a dispensa para casamento entre pessoas consanguíneas, diplomas de títulos nobiliários, licenças para casas de penhoras, orçamentos de irmandades ou confrarias e estatutos de associaçôes a serem aprovadas pelo governador civil - com exceção das Misericórdias e instituições com receita anual inferior a 50\$000 réis. Era igualmente suposto que o fundo fosse enriquecido por impostos especiais sobre lotarias estrangeiras arrecadadas pelo Tesouro português, por todos os valores arrecadados nas casas de jogo proibidas, por metade dos bens dos conventos que se extinguissem após a promulgação da Lei e por uma terça parte do produto do trabalho dos reclusos. Ainda de acordo com a lei analisada, o governo ficava autorizado a pedir dinheiro emprestado à banca para construir e mobilar o hospital em Lisboa. Certo é que o dinheiro foi angariado, porém foi canalizado para acudir a outras necessidades do Reino, no clima de instabilidade política que se viveu a nível governamental na transiçáo dos anos de oitocentos para os de novecentos.

Após a promulgação da Lei Sena deveria ter sido aprovada uma lei orgânica que estabeleceria os fundamentos administrativos e de gestão clínica dos estabelecimentos e dos círculos de assistência, e que se esperaria que enquadrasse, igualmente, o corpo de enfermeiros de cada instituição. Esta lei orgânica nunca foi formulada, como também não foram criados os círculos assistenciais, os hospitais e os asilos preconizados. Ao nível de criação de novas estruturas, o Hospital Júlio de Matos foi apenas inaugurado em 1942, o Hospital Sobral Cid em 1946 e o Hospital do Lorváo abriu somente portas na segunda metade do século XX, assim como o Hospital Magalháes de Lemos. Ao nível legislativo, foi apenas em 1911 que surgiram novos documentos para a reorganização da assistência psiquiátrica.

No entanto, em 1892 o Hospital de Rilhafoles passou a ser administrado por Miguel Bombarda, existindo melhorias significativas nessa instituição após a ação deste clínico, embora se encontrasse permanentemente com problemas de sobrelotaçáo; depois a sua morte, em 1910, Rilhafoles passou a denominar-se Hospital Miguel Bombarda, sem que a legislação fosse cumprida. No início do século XX, o Hospital de Alienados do Conde de Ferreira apresentava igualmente problemas de sobrelotação e enfrentava dificuldades financeiras, que vieram dificultar a assistência dos alienados e o seu tratamento, e, consequentemente, atrasaram a sua evolução institucional. No Portugal insular, a assistência aos alienados, na transiçáo do século XIX para o século XX, foi assegurada essencialmente pelos irmãos e irmãs religiosos da Ordem Hospitaleira dos Irmãos de $S$. João de Deus e da Congregação das Irmãs Hospitaleiras do 
Sagrado Coração de Jesus, embora estas instituiçôes não se enquadrassem naquilo que foi legislado na lei de 1889. Naquilo que diz respeito ao desenvolvimento da psiquiatria e da saúde mental em Portugal, a lei estudada assume-se de grande importância, visto ter fornecido o primeiro tecido legislativo que permitia a organização da assistência dos alienados portugueses, conquanto a mesma nunca tivesse sido concretizada. As razóes para esta não-concretização não são claras, embora seja possível afirmarmos que, possivelmente, a plena afirmação da psiquiatria como ciência apenas nos primeiros anos do século XX tenha contribuído para essa estagnação, assim como a adaptação cultural das instituiçôes assistenciais psiquiátricas ao contexto português, diferente da sistematização promovida noutros países, como por exemplo em Inglaterra.

Ainda assim, tendo sido a primeira lei desenvolvida neste contexto, serviu de base para a legislação criada em 1911, já mencionada, que teve como arquiteto Júlio de Matos, e que ajudou a alavancar a criação das instituiçóes que foram inauguradas na primeira metade do século XX, acima apresentadas. Em relaçáo à enfermagem, na lei de 1889 a mesma náo foi considerada de forma explícita no texto legislativo, porém, na legislação de 1911 preconizou-se o ensino e a preparação de enfermeiros em contextos de assistência psiquiátrica, com cursos a decorrer no Hospital Miguel Bombarda e no Hospital de Alienados do Conde de Ferreira, sendo os mesmos percursores do ensino da enfermagem de saúde mental e psiquiátrica portuguesa que se desenvolveu no século XX.

\section{Conclusáo}

A lei analisada neste trabalho foi inovadora no âmbito nacional, visto ter sido a primeira lei emanada para a assistência dos alienados portugueses, seguindo as tendências europeias e tendo em conta as ideias progressistas relacionadas com essa mesma assistência. Assim, consideramos que após a análise da Lei de 4 de julho de 1889 , do Diário do Governo n. ${ }^{\circ} 155$ de 15 de julho do mesmo ano, apresentada na Câmara dos Pares e aprovada pelo Rei D. Luiz I, o país passou a dispor, sob a ótica legislativa, de condições para iniciar os primeiros trabalhos tendo em vista a melhoria das condiçóes de vida dos alienados, tomando igualmente em consideração a relação entre o crime, a alienação e investimento no estudo da patologia mental.

O século XIX foi um período de grande importância no que diz respeito à prestação de cuidados aos alienados em Portugal. Foi nessa centúria que se verificou a afirmaçáo da psiquiatria como ciência, embora a mesma se consolidasse como tal apenas nos primeiros anos do século XX. Foram identicamente legislados aspetos que se relacionavam com a assistência psiquiátrica em estruturas próprias e de abrangência nacional, importantes para o desenvolvimento da psiquiatria e da saúde mental no país.

O século XIX, além de ter sido o tempo das personalidades que fizeram Portugal avançar relativamente à psiquiatria, foi ainda essencial para o nascimento da enfermagem como profissão em terras lusas. Este século foi igualmente fundamental para o impulso da enfermagem especializada no âmbito da psiquiatria e da saúde mental que se deu nos anos de novecentos, visto que os enfermeiros, embora não explicitamente consignados na legislação estudada, foram peças chave da assistência dos alienados nos hospitais criados exclusivamente para esse efeito. Essa lei permitiu a base para o surgimento de outros documentos legislativos que se apresentaram como primordiais aos cursos de enfermagem especializada do século XX, contribuindo assim para a evolução da profissão.

\section{Contribuiçáo de autores}

Conceptualização: Candeias, A., Macedo, E.

Tratamento de dados: Candeias, A., Macedo, E.

Metodologia: Candeias, A., Macedo, E., Esteves, A., Sá, L. Redação - preparação do rascunho original: Candeias, A., Macedo, E.

Redação - revisão e edição: Candeias, A., Macedo, E., Esteves, A., Sá, L.

\section{Referências bibliográficas}

Barahona, F. (1984). A psiquiatria em Portugal. Lisboa, Portugal: Roche. Brimblecombe, N. R. (2005). The changing relationship between mental health nurses and psychiatrists in the United Kingdom. Journal of Advanced Nursing, 49(4), 344-353. https://doi.org/10.1111/ j.1365-2648.2004.03298.x

Cardoso, C. M. (2008). Nódoas na alma: A medicina e a loucura. Lisboa, Portugal: Gradiva.

Chircop, J. (2013). Management and therapeutic regimes in two lunatic asylums in Corfu and Malta, 1837-1870. In L. Abreu \& S. Shield (Eds.), Hospital life: Theory and practice from the medieval to the modern (pp. 179-207). Berna, Switzerland: Peter Lang AG/ International Academic Publishers

Direção do Hospital Miguel Bombarda. (1949). Centenário do hospital Miguel Bombarda: Antigo hospital de Rilhafoles. Porto, Portugal: Imprensa Portuguesa.

Esteves, A. (2018). Loucos e/ou criminosos: O debate sobre a inimputabilidade em Portugal entre meados do século XIX e inícios do século XX. In M. M. Lobo de Araújo \& A. M. García (Eds.), Os marginais (séculos XVI-XIX), (pp. 279-294). Vila Nova de Famalicão, Portugal: Húmus.

Ferreira, A., Canastra, A., \& Esteves, A. (2013). Investigação em história de enfermagem: Um contributo do passado para o futuro. Revista de Enfermagem Referência, 3(11), 153-158. http://dx.doi. org/10.12707/RIII1306

Gomes, B. A. (1999). Dos estabelecimentos de alienados nos estados principais da Europa. Lisboa, Portugal: Ulmeiro.

Junior, O. C. (2011). Pesquisa documental. In T. Oguisso, P. F. Campos \& G. F. Freitas (Eds.), Pesquisa em história da enfermagem, (pp.339-362). São Paulo, Brasil: Manole.

Lei de 4 de julho de 1889. Diário do Governo n. ${ }^{\circ} 155$ de 15 de julho de 1889. Legislação Régia da Assembleia da República. Lisboa, Portugal. https://legislacaoregia.parlamento.pt/

Lopes, L. M., \& Rodrigues, M. A., (2009a). Apontamentos sobre a obra e o homem que fundou a primeira escola de enfermagem de Portugal: António Augusto da Costa Simóes. Revista de Enfermagem Referência, 2(10), 97-106. https://www.index-f.com/ referencia/2009pdf/10-97106.pdf 
Lopes, L. M., \& Rodrigues, M. A. (2009b). Os alienados em Portugal: História e estatística. Revista de Enfermagem Referência, 2(11), 135140. https://www.index-f.com/referencia/2009pdf/11-135140.pdf Mattoso, J. (1997). A Escrita da história: Teoria e métodos. Lisboa, Portugal: Editorial Estampa.

Pereira, A. L. (1986). A institucionalização da loucura em Portugal. Revista Crítica de Ciências Sociais, 21, 85-100. https://estudogeral. uc.pt/bitstream/10316/11684/1/A\%20Institucionalizacao\%20 da\%20Loucura\%20em\%20Portugal.pdf

Pulido, F. M. (1851). Relatório sobre a organização do hospital de alienados em Rilhafoles. Lisboa, Portugal: Imprensa Nacional.

República Portuguesa. (1919). Código penal português: Nova publicação oficial ordenada por Decreto de 16 de setembro de 1886 (7.a ed.). Coimbra, Portugal: Imprensa da Universidade. https://www. fd.unl.pt/Anexos/Investigacao/1274.pdf
Santa Casa da Misericórdia do Porto. (1889). Relatorio dos actos da mesa da Santa Casa da Misericórdia do Porto na sua gerência do 1. ${ }^{\circ}$ de Julho de 1888 até 30 de junho de 1889: Apresentado ao definitorio em sessão de 10 de Julho de 1889 pelo Provedor Ayres Frederico de Castro e Solla. Porto, Portugal: Typographia de A. J. da Silva Teixeira.

Sena, A. M. (2003). Os alienados em Portugal I: História e estatística II: Hospital do Conde de Ferreira. Lisboa, Portugal: Ulmeiro.

Sena, A. M. (1887). Relatorio do serviço medico e administrativo do Hospital do Conde de Ferreira: Relativo ao primeiro biennio (18831885). Porto, Portugal: Typographia Occidental.

Tucker, G. A. (1887). Lunacy in many lands. https://wellcomecollection.org/works/mc4q7qdb/items? canvas=4\&langCode=eng\&sierraId=b21293296 
Candeias, A. et al. 